\title{
HÖLDER CONTINUITY UP TO THE BOUNDARY OF SOLUTIONS TO NONLINEAR FOURTH-ORDER ELLIPTIC EQUATIONS WITH NATURAL GROWTH TERMS
}

\author{
SALVATORE BONAFEDE AND MYKHAILO V. VOITOVYCH
}

Abstract. In a bounded open set $\Omega \subset \mathbb{R}^{n}, n \geqslant 3$, we consider the nonlinear fourth-order partial differential equation $\sum_{|\alpha|=1,2}(-1)^{|\alpha|} D^{\alpha} A_{\alpha}\left(x, u, D u, D^{2} u\right)+B\left(x, u, D u, D^{2} u\right)=0$. It is assumed that the principal coefficients $\left\{A_{\alpha}\right\}|\alpha|=1,2$ satisfy the growth and coercivity conditions suitable for the energy space $\stackrel{\circ}{W}_{2, p}^{1, q}(\Omega)=\stackrel{\circ}{W}^{1, q}(\Omega) \cap \stackrel{\circ}{W}^{2, p}(\Omega), 1<p<n / 2,2 p<q<n$. The lower-order term $B\left(x, u, D u, D^{2} u\right)$ behaves as $b(u)\left\{|D u|^{q}+\left|D^{2} u\right|^{p}\right\}+g(x)$ where $g \in L^{\tau}(\Omega), \tau>n / q$. We establish the Hölder continuity up to the boundary of any solution $u \in \dot{W}_{2, p}^{1, q}(\Omega) \cap L^{\infty}(\Omega)$ by using the measure density condition on $\partial \Omega$, an interior local result and a modified Moser method with special test function.

Mathematics subject classification (2010): 35B45, 35B65, 35J40, 35 J62.

Keywords and phrases: Nonlinear elliptic high order equations, lower-order term, natural growth, Hölder continuity.

\section{REFERENCES}

[1] L. Boccardo, F. Murat, J. P. Puel, Résultats d'existence pour certains problèmes elliptiques quasilinéaires, Ann. Scuola Norm. Sup. Pisa Cl. Sci. (4), 11, 2 (1984), 213-235.

[2] L. Boccardo, F. Murat, J. P. Puel, Existence of bounded solutions for nonlinear elliptic unilateral problems, Ann. Mat. Pura Appl. (4), 152 (1988), 183-196.

[3] L. Boccardo, F. Murat, J. P. Puel, $L^{\infty}$-estimate for some nonlinear elliptic partial differential equations and application to an existence result, SIAM J. Math. Anal. 23, 2 (1992), 326-333.

[4] S. BONAFEDE, Hölder continuity of bounded generalized solutions for some degenerated quasilinear elliptic equations with natural growth terms, Comment. Math. Univ. Carolin. 59, 1 (2018), $45-64$.

[5] S. BONAFEDE, On the behaviour near the boundary of the bounded generalized solutions of quasilinear degenerate elliptic equations with natural growth terms, preprint, (2018).

[6] S. Bonafede, V. Cataldo, S. D'Asero, Hölder continuity up to the boundary of minimizers for some integral functionals with degenerate integrands, J. Appl. Math. 2007, Article ID 31819 doi:10.1155/2007/31819 (2007), 14 pages.

[7] S. BONAFEDE, F. NiCOLOSI, On the sets of regularity of solutions for a class of degenerate nonlinear elliptic fourth-order equations with $L^{1}$ data, Bound. Value Probl. 2007, (2007), 1-15.

[8] S. BONAFEDE, F. NiCOLOSI, On regularity up to the boundary of solutions to a system of degenerate nonlinear elliptic fourth-order equations, Complex Var. Elliptic Equ. 53, 2 (2008), 101-116.

[9] V. CATAldo, S. D’AsERo, F. NiCOLOS , Regularity of minimizers of some integral functionals with degenerate integrands, Nonlinear Anal. 68, 11 (2008), 3283-3293.

[10] P. Cianci, G. R. Cirmi, S. D'ASERo, S. LeOnARdi, Morrey estimates for solutions of singular quadratic nonlinear equations, Ann. Mat. Pura Appl. (4), 196, 5 (2017), 1739-1758.

[11] G. R. Cirmi, Nonlinear elliptic equations with lower order terms and $L^{1, \lambda}$-data, Nonlinear Anal. 68 , 9 (2008), 2741-2749.

[12] G. R. Cirmi, S. D'Asero, S. LeOnARdi, Fourth-order nonlinear elliptic equations with lower order term and natural growth conditions, Nonlinear Anal. 108, (2014), 66-86. 
[13] G. R. Cirmi, S. D'Asero, S. Leonardi, Gradient estimate for solutions of nonlinear singular elliptic equations below the duality exponent, Math. Methods Appl. Sci. 41, 1 (2018), 261-269.

[14] G. R. CIRMI, S. LEONARDI, Regularity results for the gradient of solutions linear elliptic equations with $L^{1, \lambda}$ data, Ann. Mat. Pura Appl. (4), 185, 4 (2006), 537-553.

[15] G. R. CIRMI, S. LEONARDI, Regularity results for solutions of nonlinear elliptic equations with $L^{1, \lambda}$ data, Nonlinear Anal. 69, 1 (2008), 230-244.

[16] G. R. CIRMI, S. LEONARDI, Higher differentiability for solutions of linear elliptic systems with measure data, Discrete Contin. Dyn. Syst. 26, 1 (2010), 89-104.

[17] G. R. Cirmi, S. LeOnARDI, Higher differentiability for the solutions of nonlinear elliptic systems with lower-order terms and $L^{1, \theta}$-data, Ann. Mat. Pura Appl. (4), 193, 1 (2014), 115-131.

[18] G. R. CiRMI, S. LEONARDI, J. STARÁ, Regularity results for the gradient of solutions of a class of linear elliptic systems with $L^{1, \lambda}$ data, Nonlinear Anal. 68, 12 (2008), 3609-3624.

[19] S. D'ASERO, On Harnack inequality for degenerate nonlinear higher-order elliptic equations, Appl. Anal. 85, 8 (2006), 971-985.

[20] S. D'ASERO, On removability of the isolated singularity for solutions of high-order elliptic equations, Complex Var. Elliptic Equ. 55, 5-6 (2010), 525-536.

[21] S. D'Asero, D. V. LARIN, Degenerate nonlinear higher-order elliptic problems in domains with fine-grained boundary, Nonlinear Anal. 64, 4 (2006), 788-825.

[22] R. GARIEPY, W. P. ZIEMER, Behavior at the boundary of solutions of quasilinear elliptic equations, Arch. Rational Mech. Anal. 56, 4 (1974), 372-384.

[23] R. GARIEPY, W. P. ZIEMER, A regularity condition at the boundary for solutions of quasilinear elliptic equations, Arch. Rational Mech. Anal. 67, 1 (1977), 25-39.

[24] D. Gilbarg and N. S. Trudinger, Elliptic Partial Differential Equations of Second Order, Springer-Verlag, Berlin, 1983.

[25] F. John, L. Nirenberg, On functions of bounded mean oscillation, Comm. Pure Appl. Math. 14, 3 (1961), 415-426.

[26] T. KILPELÄINEN, J. MALY, The Wiener test and potential estimates for quasilinear elliptic equations, Acta. Math. 172, 1 (1994), 137-161.

[27] A. A. Kovalevs KiI, Entropy solutions of the Dirichlet problem for a class of fourth-order nonlinear elliptic equations with $L^{1}$-right-hand sides, Izv. Math. 65, 2 (2001), 231-283.

[28] A. Kovalevs Ky, Entropy solutions of Dirichlet problem for a class of nonlinear elliptic high-order equations with $L^{1}$-data, Nonlinear Boundary Value Problems 12, (2002), 119-127.

[29] A. Kovalevsky, F. Nicolosi, On regularity up to the boundary of solutions to degenerate nonlinear elliptic high-order equations, Nonlinear Anal. 40, 1-8 (2000), 365-379.

[30] O. Ladyzhenskaya AND N. URAL'TSEVA, Linear and quasilinear elliptic equations, Academic Press, New York and London, 1968.

[31] S. LeONARDi, J. KotTAS, J, StARÁ, Hölder regularity of the solutions of some classes of elliptic systems in convex nonsmooth domains, Nonlinear Anal. 60, 5 (2005), 925-944.

[32] V. G. MAZ'JA, On the continuity at a boundary point of the solution of quasi-linear elliptic equations, (Russian), Vestnik Leningrad Univ. 25, 13 (1970), 42-55.

[33] J. M. RaKotoson, Résultats de régularité et d'existence pour certaines équations elliptiques quasi linéaires, C. R. Acad. Sci. Paris, Série I, 302, 16 (1986), 567-570.

[34] J. M. RAKOTOSON, Réarrangement relatif dans les équations elliptiques quasi-linéaires avec un second membre distribution: Application à un théorème d'existence et de régularité, J. Differential Equations 66, 3 (1987), 391-419.

[35] I. V. SKRYPNIK, Nonlinear higher order elliptic equations, (Russian), Naukova dumka, Kiev, 1973.

[36] I. V. SKRYPNIK, Higher order quasilinear elliptic equations with continouos generalized solutions, Differential Equations 14, 6 (1978), 786-795.

[37] I. V. SKRYPNIK, A criterion for regularity of a boundary point for quasilinear elliptic equations, (Russian), Dokl. Akad. Nauk SSSR, 274, 5 (1984), 1040-1044.

[38] I. V. SKRYPNIK, Regularity of a boundary point for a higher-order quasilinear elliptic equation, Proc. Steklov Inst. Math. 200, 2 (1993), 339-351.

[39] M. V. Voitovich, Existence of bounded solutions for a class of nonlinear fourth-order equations, Differ. Equ. Appl. 3, 2 (2011), 247-266. 
[40] M. V. VoITOVICH, Existence of bounded solutions for nonlinear fourth-order elliptic equations with strengthened coercivity and lower-order terms with natural growth, Electron. J. Differential Equations 2013, 102 (2013), 1-25.

[41] M. V. Voitovich, On the existence of bounded generalized solutions of the Dirichlet problem for a class of nonlinear high-order elliptic equations, J. Math. Sci. (N. Y.), 210, 1 (2015), 86-113.

[42] M. V. VoITOVYCH, Hölder continuity of bounded generalized solutions for nonlinear fourth-order elliptic equations with strengthened coercivity and natural growth terms, Electron. J. Differential Equations 2017, 63 (2017), 1-18. 